\title{
Synthesis of meta-substituted monodentate phosphinite ligands and implication in hydroformylation ${ }^{\dagger}$
}

\author{
SATEJ S DESHMUKH ${ }^{a}$, SHAHAJI R GAIKWAD ${ }^{a}$, SWECHCHHA PANDEYa, \\ PRAMOD S MALI ${ }^{\mathrm{b}}$ and SAMIR H CHIKKALI ${ }^{\mathrm{a}, \mathrm{c}, *}$ \\ ${ }^{a}$ Polymer Science and Engineering Division, CSIR-National Chemical Laboratory, Dr. Homi Bhabha Road, \\ Pune, Maharashtra 411 008, India \\ ${ }^{\mathrm{b}}$ Central NMR facility, CSIR-National Chemical Laboratory, Dr. Homi Bhabha Road, Pune, \\ Maharashtra 411 008, India \\ ${ }^{\mathrm{c}}$ Academy of Scientific and Innovative Research (AcSIR), Anusandhan Bhawan, 2 Rafi Marg, \\ New Delhi 110 001, India \\ E-mail: s.chikkali@ncl.res.in
}

MS received 25 April 2017; revised 9 July 2017; accepted 9 July 2017

\begin{abstract}
Synthesis of meta-substituted phosphinite ligands $3,3^{\prime}$-(methoxyphosphanediyl)bis $(N, N$ diethylaniline) (4a) and methoxybis(3-methoxyphenyl)phosphane (4b), in high yields, has been demonstrated. Typical phosphorus chemical shift between 110-120 ppm, appearance of methoxy protons and corresponding carbon, as well as ESI-MS spectra unambiguously confirmed the existence of phosphinite ligands $\mathbf{4 a}$ and $\mathbf{4 b}$. To demonstrate the synthetic usefulness of $\mathbf{4 a}$ and $\mathbf{4 b}$, these ligands were tested in the rhodium catalyzed hydroformylation of 1-octene. The diethylamine substituted ligand $\mathbf{4 a}$ was found to be highly active, whereas $4 \mathbf{b}$ was less reactive but revealed slightly better regioselectivity of $62 \%$ under optimized conditions. Additionally, $4 \mathbf{a}$ and $\mathbf{4 b}$ were found to catalyze the hydroformylation of styrene, 1-undecenol and 1,1-disubstituted functional olefin, methyl methacrylate. Both the ligands displayed excellent conversion of styrene, and $\mathbf{4 b}$ revealed an excellent branch selectivity of 75\%. Although 1-undecenol proved to be amenable to hydroformylation (85$90 \%$ conversion to aldehyde), both the ligands failed to discriminate between the linear and branched products. Substrate methyl methacrylate proved to be highly challenging and reduced conversion (between 33-42\%) was observed under optimized conditions. Ligand $\mathbf{4 a}$ was found to be highly selective towards linear aldehyde ( $81 \%$ linear selectivity).
\end{abstract}

Keywords. Phosphinite ligands; $m$-phosphinites; rhodium catalyst; hydroformylation.

\section{Introduction}

Manipulating the reactivity of a metal center has been central to the development of homogeneous catalysis and a variety of ligands have been employed to tame the metal. ${ }^{1}$ Among the wide array of ligands, application of organo-phosphorus compounds in homogenous catalysis has grown enormously in the recent past as they offer control over reactivity, selectivity or both. ${ }^{2}$ Hence, synthesis of organo-phosphorus ligands such as phosphine, ${ }^{3}$ phosphinite, ${ }^{4}$ phosphonite,${ }^{5}$ phosphite,${ }^{6}$ phosphoramidite, ${ }^{7}$ etc., has become indispensable. ${ }^{8}$ Among

\footnotetext{
*For correspondence

$\dagger$ Dedicated to Prof. K C Kumara Swamy on the occasion of his 60th birth anniversary.
}

these organo-phosphorus ligands, compounds bearing two $\mathrm{P}-\mathrm{C}$ and one $\mathrm{P}-\mathrm{O}$ bond are named as phosphinite. The electronic quantification measured in terms of $\chi$ parameter ${ }^{9}$ and steric crowding calculated by Tolman cone angle ${ }^{10}$ ranks them between phosphine and phosphonite. Due to the characteristic electronic and steric properties phosphinite offer, they have been popularly employed in organic transformations such as Mitsunobu reaction and Arbuzov reaction, to name a few. ${ }^{11}$ Apart from organic synthesis, phosphinite ligands find applications in a variety of metal catalyzed transformations as depicted in Figure 1. Notable among these are hydrogenation, transfer hydrogenation, Suzuki-Miyaura coupling, Mizoroki-Heck coupling, hydroformylation, and allylation. ${ }^{12}$ Recent surge in phosphinite derived pincer

Electronic supplementary material: The online version of this article (doi:10.1007/s12039-017-1341-z) contains supplementary material, which is available to authorized users. 


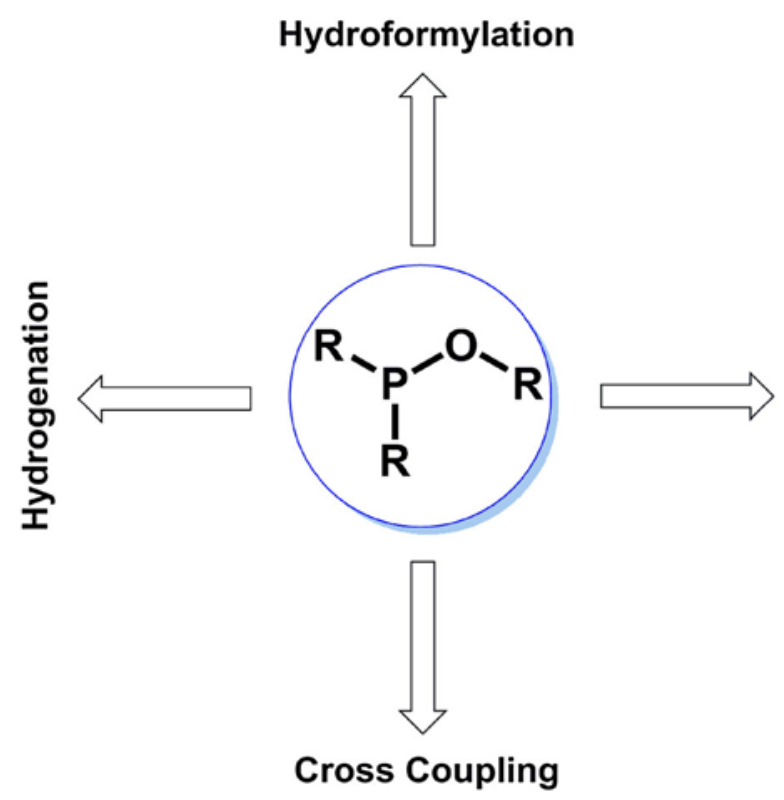

Figure 1. Applications of phosphinite ligands in homogeneous catalysis.

complexes has opened up new avenues and unexplored territories. ${ }^{13}$

Given the significance of phosphinites, there have been consistent efforts to prepare them in minimum steps. Literature survey suggests that two synthetic protocols have been commonly utilized to synthesize phosphinites. In a very frequently used method, chlorophosphines have been treated with alcohols to yield desired phosphinites. ${ }^{14}$ In a second method, Grignard reagent is reacted with methoxy chlorophosphines ${ }^{15}$ or substituted aryls are lithiated and treated with aminodichlorophosphine in the first step, which is then followed by methanolysis. ${ }^{16}$ Above two methods are very frequently used to synthesize ortho- and para-substituted phosphinite ligands. ${ }^{17}$ However, synthesis of meta-substituted phosphinite ligands is rarely reported. ${ }^{18}$ This is most likely due to the classical mesomeric effect, which imparts higher probability of substitution/addition at ortho and para-position and disfavors substitution/addition at meta-position. In addition, effect of meta-substitution on catalytic activity or selectivity of a specific reaction is still in its infancy. ${ }^{19}$ In particular, phosphinites are the ligands of choice for some reactions like hydroformylation due to their strong $\pi$-accepting character and investigating the effect of $m e t a$-substitution in this reaction will be of great significance. ${ }^{20}$ The character and position of a substituent on ligand backbone can substantially tailor the catalytic properties and might alter the reactivity or selectivity of a catalytic reaction. At times, it can completely shut down one reaction pathway and improvise the other pathway. In this context, it is highly desirable to develop a synthetic methodology that can provide direct access to meta-substituted phosphinites.

Herein, we report a synthetic method that provides direct access to meta-substituted phosphinites with electron donating substituents. Synthetic utility of the meta-substituted phosphinites has been demonstrated by evaluating the performance of these ligands in the hydroformylation of 1-octene, styrene, 1-undecenol and methyl methacrylate.

\section{Experimental}

\subsection{General}

All experimental manipulations were performed under an inert atmosphere of dry nitrogen or argon using standard Schlenk techniques or glove box. Requisite solvents were purified by conventional procedures and distilled prior to usage. 1,1-dichloro- $N, N$-diethylphosphanamine was prepared according to published procedure. ${ }^{21}$ The rhodium precursor $\left[\mathrm{Rh}(\mathrm{acac})(\mathrm{CO})_{2}\right]$ was procured from Acros Organics and used without further purification. Syngas (1:1 mixture of $\mathrm{CO}: \mathrm{H}_{2}$ ) was supplied by Ms. Vadilal Chemicals Ltd., Pune, India. Common reagents were obtained from local suppliers (Spectrochem Pvt. Ltd.; Avra Synthesis Pvt. Ltd.; Thomas Baker Pvt. Ltd., etc.) and used after purification. Hydroformylation was run in a high-pressure reactor (Amar Equipment Pvt. Ltd.) equipped with pressure regulators and safety rupture valve. Solution NMR spectra were recorded on a Bruker Avance 200, 400 and $500 \mathrm{MHz}$ instruments. Coupling constants are given as absolute values. Multiplicities are given as follows; s: singlet, d: doublet, t: triplet, m: multiplet, dd: doublet of doublet. Mass spectra were recorded on Thermo scientific Q-Exactive (the column specification is Hypersil gold C18 column diameter, $50 \times 2.1 \mathrm{~mm}$; particle size, $1.9 \mu \mathrm{m}$; mobile phase used, $90 \%$ methanol $+10 \%$ water + $0.1 \%$ formic acid) instrument. GC analysis for 1-octene was carried out on an Agilent 7890B GC system using HP-05 column $(30 \mathrm{~m} \times 320 \mu \mathrm{m} \times 0.25 \mu \mathrm{m})$, split ratio $30: 1$, column flow $1.5 \mathrm{~mL} / \mathrm{min}$., injector temperature of $260^{\circ} \mathrm{C}$, detector temperature of $330^{\circ} \mathrm{C}$, and argon carrier gas. Temperature program: Initial temperature $70^{\circ} \mathrm{C}$, hold for $1 \mathrm{~min}$; ramp 1: $4^{\circ} \mathrm{C} / \mathrm{min}$ to $120^{\circ} \mathrm{C}$; $\operatorname{ramp} 2: 10^{\circ} \mathrm{C} / \mathrm{min}$. to $250^{\circ} \mathrm{C}$; ramp 3: $20^{\circ} \mathrm{C} / \mathrm{min}$. to $320^{\circ} \mathrm{C}$, hold for $2 \mathrm{~min}$. Retention time for $1-$ octene $=2.1 \mathrm{~min}$; branched aldehydes $=6.0-7.1 \mathrm{~min}$; linear aldehyde $=8.1 \mathrm{~min}$ (Figure S28 in SI). GC analysis for styrene was carried out on an Agilent 7890B GC system using Supelco $\beta$-dex column $(30 \mathrm{~m} \times 0.25 \mathrm{~mm} \times 0.25 \mu \mathrm{m})$, split ratio $30: 1$, inlet temperature of $220^{\circ} \mathrm{C}$, and argon carrier gas. Temperature program: Initial temperature $100^{\circ} \mathrm{C}$, hold for $2 \mathrm{~min}$.; ramp 1: $2^{\circ} \mathrm{C} / \mathrm{min}$ to $160^{\circ} \mathrm{C}$; ramp $2: 20^{\circ} \mathrm{C} / \mathrm{min}$ to $210^{\circ} \mathrm{C}$, hold for 2 min Retention time for styrene $=7.3 \mathrm{~min}$.; hydrogenated product (ethyl benzene) $=6.3 \mathrm{~min}$; for branched aldehyde $=$ 17.0 min., linear aldehyde $=23.2$ minute (Figures S30-S31 in SI). 


\subsection{Synthesis of 3-bromo-N,N-diethylaniline (2a)}<smiles>CCNc1cccc(Br)c1</smiles>

Precursor 2a was prepared by a modified literature procedure. $^{22}$ 3-bromoaniline $(5.0 \mathrm{~g}, 29.07 \mathrm{mmol})$ was added to a suspension of sodium hydride $(\mathrm{NaH})(1.5 \mathrm{~g}, 63.95 \mathrm{mmol})$ in tetrahydrofuran (THF) $(50 \mathrm{~mL})$ at $0^{\circ} \mathrm{C}$ under positive argon flow and the reaction mixture was stirred for $2 \mathrm{~h}$. Next, ethyl iodide $(9.97 \mathrm{~g}, 63.95 \mathrm{mmol})$ was added to the above suspension and the violet coloured reaction mixture was stirred at room temperature for $5 \mathrm{~h}$. Finally, the reaction was quenched with water, and organic layer was extracted with ethyl acetate (three times). The combined extracts were washed with brine and dried over sodium sulfate. Volatiles were evaporated under vacuum and the resultant residue was purified by column chromatography (using pet-ether) to produce compound $\mathbf{2 a}$ in $40 \%$ isolated yield. ${ }^{1} \mathrm{H} \mathrm{NMR}(400 \mathrm{MHz}$, $\left.\mathrm{CDCl}_{3}\right): \delta=7.08(\mathrm{dd}, J=8.0,7.6 \mathrm{~Hz}, 1 \mathrm{H}), 6.80(\mathrm{~m}, 2 \mathrm{H})$, $6.60(\mathrm{dd}, J=7.7,1.83 \mathrm{~Hz}, 1 \mathrm{H}), 3.35(\mathrm{q}, J=6.87 \mathrm{~Hz}, 4 \mathrm{H})$, $1.20(\mathrm{t}, J=6.87 \mathrm{~Hz}, 6 \mathrm{H})$.

\subsection{Synthesis of 3,3'-((diethylamino) \\ phosphanediyl)bis( $N, N$-diethylaniline) (3a)}<smiles>CCNc1cccc(P(c2cccc(NCC)c2)N(CC)CC)c1</smiles>

To a solution of $N, N$-diethyl-3-bromoaniline (2a) (5 g, $21.91 \mathrm{mmol})$ in diethyl ether $\left(\mathrm{Et}_{2} \mathrm{O}\right)$ was added n-butyl lithium ( $n$-BuLi) $(15.06 \mathrm{~mL}, 24.10 \mathrm{mmol})$ at $0^{\circ} \mathrm{C}$. After complete addition, reaction mixture was slowly warmed to room temperature and was stirred for $3 \mathrm{~h}$. Next, a solution of 1,1dichloro- $N, N$-diethylphosphanamine $(1.90 \mathrm{~g}, 10.95 \mathrm{mmol})$ in diethyl ether was added over $7 \mathrm{~min}$ to the above reaction mixture at $0^{\circ} \mathrm{C}$ with constant stirring. The reaction mixture was stirred for $12 \mathrm{~h}$ at $25^{\circ} \mathrm{C}$. The resultant lithium bromide was separated by cannula filtration and the filtrate was evaporated under reduced pressure to yield yellow coloured residue. The residue was extracted in hexane to isolated yield $72 \%(6.3 \mathrm{~g})$ of 3,3'-((diethylamino)phosphanediyl)bis $(N, N$ diethylaniline) (3a). ${ }^{1} \mathrm{H}$ NMR $\left(500 \mathrm{MHz}, \mathrm{C}_{6} \mathrm{D}_{6}\right): \delta=7.22$ $\left(\mathrm{t}, J_{\mathrm{H}-\mathrm{H}}=8.77 \mathrm{~Hz}, 2 \mathrm{H}\right), 7.07(\mathrm{~m}, 4 \mathrm{H}), 6.55\left(\mathrm{dd}, J_{\mathrm{H}-\mathrm{H}}=2\right.$ $\mathrm{Hz}, 2 \mathrm{H}), 3.23(\mathrm{~m}, 4 \mathrm{H}), 3.01\left(\mathrm{qd}, J_{\mathrm{H}-\mathrm{H}}=2 \mathrm{~Hz}, 8 \mathrm{H}\right), 1.00(\mathrm{t}$, $\left.J_{\mathrm{H}-\mathrm{H}}=7.06 \mathrm{~Hz}, 6 \mathrm{H}\right), 0.90\left(\mathrm{t}, J_{\mathrm{H}-\mathrm{H}}=7.25 \mathrm{~Hz}, 12 \mathrm{H}\right) .{ }^{13} \mathrm{C}$ NMR (125 MHz, $\left.\mathrm{C}_{6} \mathrm{D}_{6}\right): \delta=148.2(\mathrm{~d}, J=6.82 \mathrm{~Hz}), 142.5$ $\left(\mathrm{d}, J_{\mathrm{P}-\mathrm{C}}=6.82 \mathrm{~Hz}\right), 129.6\left(\mathrm{~d} J_{\mathrm{C}-\mathrm{H}}=6.68 \mathrm{~Hz}\right), 120.4(\mathrm{~d}$, $\left.J_{\mathrm{C}-\mathrm{H}}=19.07 \mathrm{~Hz}\right), 116.7\left(\mathrm{~d}, J_{\mathrm{C}-\mathrm{H}}=23.8 \mathrm{~Hz}\right), 112.6,45.3$ $\left(\mathrm{d}, J_{\mathrm{C}-\mathrm{H}}=15.26 \mathrm{~Hz}\right), 44.2,15.3\left(\mathrm{~d}, J_{\mathrm{C}-\mathrm{H}}=2 \mathrm{~Hz}\right), 13.1 .{ }^{31} \mathrm{P}$ $\operatorname{NMR}\left(500 \mathrm{MHz}, \mathrm{C}_{6} \mathrm{D}_{6}\right): \delta=64.64$.

\subsection{Synthesis of 3,3'-(methoxyphosphanediyl) bis( $N, N$-diethylaniline) (4a)}<smiles>CCNc1cccc(P(OC)c2cccc(NCC)c2)c1</smiles>

Compound 3a (0.5 g, $1.25 \mathrm{mmol})$ was dissolved in $20 \mathrm{~mL}$ methanol $(\mathrm{MeOH})$ and stirred for $8 \mathrm{~h}$ at room temperature. Volatiles were evaporated to obtain solid residue which was extracted with hexane $(2 \times 10 \mathrm{~mL})$. The resultant hexane was evaporated under reduced pressure to obtain yellow coloured compound in quantitative $(>99 \%)$ yield $(0.444 \mathrm{~g})$, which was identified as 4a. ${ }^{1} \mathrm{H}$ NMR $\left(500 \mathrm{MHz}, \mathrm{C}_{6} \mathrm{D}_{6}\right): \delta=7.30$ $(\mathrm{m}, 6 \mathrm{H}), 6.64\left(\mathrm{dd}, J_{\mathrm{H}-\mathrm{H}}=1.83,8.24 \mathrm{~Hz}, 2 \mathrm{H}\right), 3.66(\mathrm{~d}$, $\left.J_{\mathrm{H}-\mathrm{H}}=13.43 \mathrm{~Hz}, 3 \mathrm{H}\right), 3.07\left(\mathrm{q}, J_{\mathrm{H}-\mathrm{H}}=7.02 \mathrm{~Hz}, 8 \mathrm{H}\right), 0.96$ $\left(\mathrm{t}, J_{\mathrm{H}-\mathrm{H}}=7.02 \mathrm{~Hz}, 12 \mathrm{H}\right) .{ }^{13} \mathrm{C} \mathrm{NMR}\left(125 \mathrm{MHz}, \mathrm{C}_{6} \mathrm{D}_{6}\right)$ : $\delta=148.2\left(\mathrm{CNEt}_{2}, \mathrm{Ar}\right), 143.8(\mathrm{CPOMe}, \mathrm{Ar}), 129.9(\mathrm{CH}$, $\mathrm{Ar}), 118.7$ ( $\mathrm{CH}, \mathrm{Ar}), 114.5$ ( $\mathrm{CH}, \mathrm{Ar}), 113.5$ ( $\mathrm{CH}, \mathrm{Ar}), 56.6$ $\left(\mathrm{OCH}_{3}\right), 44.8\left(\mathrm{NCH}_{2} \mathrm{CH}_{3}\right), 13.0\left(\mathrm{NCH}_{2} \mathrm{CH}_{3}\right) .{ }^{31} \mathrm{P} \mathrm{NMR}$ $\left(500 \mathrm{MHz}, \mathrm{CDCl}_{3}\right): \delta=120.4$. ESI-MS (+ve mode) $\mathrm{m} / \mathrm{z}=$ $359.22[\mathrm{M}+\mathrm{H}]^{+}$.

\subsection{Synthesis of $N, N$-diethyl-1,1-bis \\ (3-methoxyphenyl)phosphanamine (3b)}<smiles>CCN(CC)P(c1cccc(OC)c1)c1cccc(OC)c1</smiles>

A solution of 3-bromoanisole $(5 \mathrm{~g}, 26.73 \mathrm{mmol})$ in diethyl ether $(60 \mathrm{~mL})$ was treated with $n$-BuLi $(18.4 \mathrm{~mL}, 29.4 \mathrm{mmol})$ at $0^{\circ} \mathrm{C}$. After complete addition, the reaction mixture was slowly warmed to room temperature and was stirred for next 3 h. 1,1-dichloro- $N, N$-diethylphosphanamine (2.32 g, 13.3 $\mathrm{mmol}$ ) was slowly (over $7 \mathrm{~min}$ ) added to above reaction mixture at $0^{\circ} \mathrm{C}$ with constant stirring. The reaction was stirred for $12 \mathrm{~h}$ at $25^{\circ} \mathrm{C}$ and lithium bromide salt was separated by cannula filtration. The resultant solution was evaporated under reduced pressure to yield a yellow coloured residue. The residue was extracted in hexane to isolate $\mathbf{3 b}$ in $56.6 \%$ $(3.94 \mathrm{~g})$ yield. ${ }^{1} \mathrm{H}$ NMR $\left(500 \mathrm{MHz}, \mathrm{CDCl}_{3}\right): \delta=7.22(\mathrm{t}, J$ 
$=7.63 \mathrm{~Hz}, 2 \mathrm{H}), 6.97(\mathrm{~m}, 4 \mathrm{H}), 6.82(\mathrm{~d}, J=8.39 \mathrm{~Hz}, 2 \mathrm{H})$,

3.73 (s, 6H), 3.07 (q, $J=7.25 \mathrm{~Hz}, 4 \mathrm{H}), 0.95(\mathrm{t}, J=7.25$ $\mathrm{Hz}, 6 \mathrm{H}) .{ }^{13} \mathrm{C} \mathrm{NMR}\left(125 \mathrm{MHz}, \mathrm{CDCl}_{3}\right): \delta=159.4(\mathrm{~d}, J=$ $6.68 \mathrm{~Hz}), 141.9(\mathrm{~d}, J=15.26 \mathrm{~Hz}), 129.1(\mathrm{~d}, J=6.68 \mathrm{~Hz})$, $124.3(\mathrm{~d}, J=20.03 \mathrm{~Hz}), 117.2(\mathrm{~d}, J=20.98 \mathrm{~Hz}), 113.8,55.1$, $44.5(\mathrm{~d}, J=15.26 \mathrm{~Hz}), 14.5 .{ }^{31} \mathrm{P} \mathrm{NMR}\left(500 \mathrm{MHz}, \mathrm{CDCl}_{3}\right)$ : $\delta=62.34$.

\subsection{Synthesis of methoxybis(3-methoxyphenyl)} phosphane (4b)

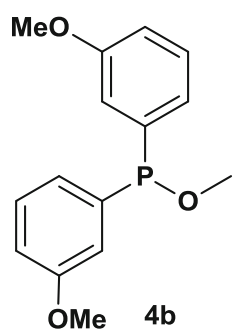

Compound 3b (0.5 g, $15.75 \mathrm{mmol})$ was dissolved in $20 \mathrm{~mL}$ $\mathrm{MeOH}$ and stirred for $8 \mathrm{~h}$ at room temperature. Volatiles were evaporated and the resultant residue was extracted with hexane $(2 \times 10 \mathrm{~mL})$. The hexane solution was evaporated under reduced pressure to obtain yellow coloured compound in quantitative yield (97.5\%), $0.424 \mathrm{~g}$ (15.36 mmol), which was identified as $\mathbf{4 b} .{ }^{1} \mathrm{H}$ NMR $\left(500 \mathrm{MHz}, \mathrm{CDCl}_{3}\right): \delta=7.28$ $(\mathrm{d}, J=6.49 \mathrm{~Hz}, 2 \mathrm{H}), 7.04(\mathrm{~m}, 4 \mathrm{H}), 6.86(\mathrm{~d}, J=7.25 \mathrm{~Hz}$, 2H), 3.76 (s, 6H), 3.64 (d, $J=14.11 \mathrm{~Hz}, 3 \mathrm{H}) .{ }^{13} \mathrm{C}$ NMR $(125$ $\left.\mathrm{MHz} \mathrm{CDCl}_{3}\right): \delta=159.6(\mathrm{~d}, J=7.63 \mathrm{~Hz}), 143.1(\mathrm{~d}, J=$ $19.07 \mathrm{~Hz}), 129.6(\mathrm{~d}, J=7.6 \mathrm{~Hz}), 122.8(\mathrm{~d}, J=22.8 \mathrm{~Hz})$, $115.4,115.3,57.0(\mathrm{~d}, J=19.07 \mathrm{~Hz}), 55.3 .{ }^{31} \mathrm{P}$ NMR $(500$ $\mathrm{MHz}_{\mathrm{CDCl}}$ ): $\delta=116.81$. ESI-MS (+ve mode) $\mathrm{m} / \mathrm{z}=277.09$ $[\mathrm{M}+\mathrm{H}]^{+}$.

\subsection{General procedure for hydroformylation}

In a typical hydroformylation experiment a stainless steel autoclave $(450 \mathrm{~mL})$ equipped with pressure regulator and a safety valve was used. Individual vials were charged with metal precursor $\left\{\left[\mathrm{Rh}(\mathrm{acac})(\mathrm{CO})_{2}\right](2 \mathrm{mg})\right\}$, ligand (as in Tables 1 and 2$)$, solvent ( $1 \mathrm{~mL})$, substrate (100 equiv.) and stirring bars in a glove box. The vials were transferred to autoclave and the autoclave was purged three times with syngas ( $\mathrm{CO}: \mathrm{H}_{2}=1: 1$ ) before pressurizing it to the desired pressure. Suitable temperature and pressure were maintained during the reaction. After completion of the reaction, the autoclave was cooled to $0^{\circ} \mathrm{C}$, and excess gas was vented off in a wellventilated fume-hood. The conversion and regio-selectivities were determined by proton NMR spectroscopy and gas chromatography.

\section{Results and Discussion}

\subsection{Ligand synthesis}

The precursor $\mathbf{2 a}$ was prepared by a modified literature procedure. $^{22}$ 3-bromoaniline (1a) was treated with ethyl iodide in presence of a base $(\mathrm{NaH})$ and purification by column chromatography produced $\mathbf{2 a}$ in $40 \%$ isolated yield. After confirming the existence of $\mathbf{2} \mathbf{a}$, it was treated with $n$-butyl lithium at $0^{\circ} \mathrm{C}$, which was followed by addition of 1,1-dichloro- $N, N$-diethylphosphanamine (in diethyl ether). The reaction mixture was stirred for 12 $\mathrm{h}$, the by-product ( $\mathrm{LiBr}$ ) was separated by filtration and the filtrate was concentrated under reduced pressure to produce yellow viscous oily residue. Extraction of the residue with hexane produced anticipated 3,3'((diethylamino)phosphanediyl)bis $(N, N$-diethylaniline) 3a in $72 \%$ isolated yield. Single resonance at 64.6 ppm in ${ }^{31} \mathrm{P}$ NMR (Figure S2 in SI) suggested formation of 3a. The phosphorus NMR findings were corroborated by proton NMR, which revealed characteristic triplet at $1.0 \mathrm{ppm}$ for the methyl protons and a multiplet at 3.23 ppm for the methylene protons. The $\mathrm{P}-\mathrm{C}$ bond formation was confirmed by ${ }^{13} \mathrm{C}$ NMR, which displayed a peak at $142.5 \mathrm{ppm}$ corresponding to the P-coupled carbon (SI Figure S3-S5).

In the final step to phosphinite, isolated $\mathbf{3 a}$ was treated with methanol and the progress of the reaction was monitored by ${ }^{31} \mathrm{P}$ NMR spectroscopy. The phosphorus resonance at $64.6 \mathrm{ppm}$ slowly disappears with a concomitant appearance of a new peak at 120.4 ppm (Figure S6). Thus, ${ }^{31} \mathrm{P}$ NMR indicated completion of the reaction in 8 hours, after which volatiles were evaporated to produce the anticipated $\mathbf{4 a}$ in near quantitative yield (>99\%) (Scheme 1). A singlet in ${ }^{31} \mathrm{P}$ NMR at 120.4 ppm indicated formation of P-OMe bond, whereas the doublet at 3.67 in proton NMR further supported formation of $\mathbf{4 a}$. The existence of $\mathbf{4 a}$ was unambiguously ascertained using combination of 1-2D NMR and mass spectroscopy. The formation of $\mathrm{P}-\mathrm{OMe}$ was illustrated by recording a long range $\mathrm{P}-\mathrm{H}$ correlation (HMBC) NMR spectrum, which revealed a cross peak between a phosphorus resonance at 120.4 and a proton resonance at $3.67 \mathrm{ppm}$ (Figure 2). The NMR findings were further corroborated by ESI-MS that revealed a molecular ion peak at $\mathrm{m} / \mathrm{z}=359.22[\mathrm{M}+\mathrm{H}]^{+}$(Figure S12).

In our attempts to test the generality of the synthetic protocol, we extended the scope to methoxy derivatives. In this case, commercially available 3-bromoanisole (2b) was lithiated using $n$-BuLi and the resultant salt was treated with 1,1-dichloro- $N, N$-diethylphosphanamine. The reaction mixture was stirred for $12 \mathrm{~h}$, solids were separated by filtration and the filtrate was evaporated 
Table 1. Rhodium catalyzed hydroformylation of 1-octene using $\mathbf{4 a - b}{ }^{\text {a }}$

\begin{tabular}{|c|c|c|c|c|c|c|c|}
\hline \multicolumn{2}{|c|}{ 1-octene } & & & \multicolumn{2}{|c|}{ Linear (I) } & \multicolumn{2}{|c|}{ Branched (b) } \\
\hline$\overline{\text { Run }}$ & Ligand & L/M Ratio & Temp. $\left({ }^{\circ} \mathrm{C}\right)$ & $\mathrm{CO} / \mathrm{H}_{2}$ (bar) & Time (hrs) & Conversion $^{\mathrm{b}}(\%)$ & l:b selectivity ${ }^{b}$ \\
\hline 1 & $4 a$ & 2 & 100 & 10 & 16 & 92 & 44:56 \\
\hline 2 & $4 a$ & 4 & 100 & 10 & 16 & 94 & $51: 49$ \\
\hline 3 & $4 a$ & 6 & 100 & 10 & 16 & 97 & $55: 45$ \\
\hline 4 & $4 a$ & 4 & 100 & 5 & 16 & 60 & 39:61 \\
\hline 5 & $4 a$ & 4 & 100 & 20 & 16 & 97 & 49:51 \\
\hline 6 & $4 a$ & 4 & 120 & 10 & 16 & 37 & $50: 50$ \\
\hline 7 & $4 a$ & 4 & 80 & 10 & 16 & 70 & $15: 85$ \\
\hline 8 & $4 b$ & 2 & 100 & 10 & 16 & 36 & 44:56 \\
\hline 9 & $4 b$ & 4 & 100 & 10 & 16 & 33 & $47: 53$ \\
\hline 10 & $4 b$ & 6 & 100 & 10 & 16 & 24 & 49:51 \\
\hline 11 & $4 b$ & 4 & 100 & 5 & 16 & 15 & $52: 48$ \\
\hline 12 & 4b & 4 & 100 & 20 & 16 & 87 & $54: 46$ \\
\hline 13 & $4 b$ & 4 & 120 & 10 & 16 & 56 & $62: 38$ \\
\hline 14 & $4 b$ & 4 & 80 & 10 & 16 & 53 & $30: 70$ \\
\hline $15^{\mathrm{c}}$ & 5 & 5 & 100 & 20 & 4 & 96 & $67: 33$ \\
\hline $16^{\mathrm{c}}$ & 6 & 2 & 60 & 30 & 6 & 98 & 69:31 \\
\hline
\end{tabular}

${ }^{\mathrm{a} C o n d i t i o n s:}\left[\mathrm{Rh}(\mathrm{acac})(\mathrm{CO})_{2}\right]=2 \mathrm{mg}$, Solvent: toluene $(1 \mathrm{~mL}),{ }^{\mathrm{b}}$ Conversion and regioselectivity were determined by GC, ${ }^{\mathrm{c} C o m p a r i s i o n}$ with literature reported ligands $\mathbf{5}$ and $\mathbf{6}$ (see Chart 1 for details). Note that the reaction conditions reported in these runs may not be same as run $1-14$. For report on ligand $\mathbf{5}$, see Ref. ${ }^{19}$ and for the report on ligand $\mathbf{6}$, see Ref. ${ }^{24}$

under vacuum. The resultant residue was extracted with hexane and evaporation of hexane solution under reduced pressure produced highly viscous material in $56.6 \%$ isolated yield, which was identified as $N, N$ diethyl-1,1-bis(3-methoxyphenyl)phosphanamine (3b). Appearance of a ${ }^{31} \mathrm{P}$ NMR resonance at $62.34 \mathrm{ppm}$ along with proton signals at 0.95 and $3.07 \mathrm{ppm}$ for methyl and methylene protons respectively confirmed the formation of C-P bond. In a second step, suitable quantity of methanol was added to $\mathbf{3} \mathbf{b}$ and the reaction solution was stirred for $8 \mathrm{~h}$. The resultant compound was purified by extraction with hexane to produce a semisolid material, which was analysed by various techniques to establish the identity. Thus, the ${ }^{31} \mathrm{P}$ NMR spectrum of isolated material revealed a new peak at $116.8 \mathrm{ppm}$, which can be comfortably assigned to the anticipated product methoxybis(3-methoxyphenyl)phosphane $\mathbf{4 b}$. Consistent with these results, the proton NMR of above material disclosed decay of the diethyl amine signals with simultaneous emergence of a new peak at $3.64 \mathrm{ppm}$ (that can be easily assigned to methoxy protons directly located on phosphorus). The NMR findings were further supported by ESI-MS (+ve mode) which revealed a molecular ion peak at $\mathrm{m} / \mathrm{z}=277.09[\mathrm{M}+\mathrm{H}]^{+}$(Figure 3). The observed splitting pattern closely matches with the simulated splitting pattern (Figure 3), authenticating the existence of $\mathbf{4 b}$.

\subsection{Rhodium catalyzed hydroformylation of 1-octene}

Hydroformylation of alkenes is arguably one of the largest processes in industrial homogeneous catalysis. ${ }^{23}$ Phosphorus ligands play prominent role in the hydroformylation of variety of substrates. Among the phosphorus ligands, phosphinites stand out as a good $\sigma$-donor and strong $\pi$-acceptor ligands. Therefore, rhodium catalyzed hydroformylation of 1-octene was selected as a test reaction to evaluate the performance of newly prepared meta-substituted phosphinite ligands. After the successful synthesis of meta-phosphinites $\mathbf{4 a}$ b, we set out to evaluate their performance in the hydroformylation of 1-octene and Table 1 summarizes the most important results. It is anticipated that the necessary catalyst for hydroformylation is generated in situ upon reaction of rhodium precursor $\left[\mathrm{Rh}(\mathrm{acac})(\mathrm{CO})_{2}\right]$ and the ligand $(\mathbf{4 a} / \mathbf{4} \mathbf{b})$, in presence of alkene under syngas pressure. Preliminary screening of ligand to metal ratio pointed to an optimal ligand to metal ratio of 4 with a competitive conversion of $94 \%$ (Table 1 , run $1-$ 3 ). Keeping the L/M ratio 4, we screened the effect of syngas pressure on conversion and regioselectivity. As it is evident from Table 1, either reducing the pressure to 5 bars or increasing it to 20 bars had negative impact and led to reduced selectivity (Table 1 , run 4-5). Thus, syngas pressure of 10 bars seems to be the optimal pres- 
Table 2. Rhodium catalyzed hydroformylation of styrene (S2), 1-undecenol (S3) and methyl methacrylate (S4). ${ }^{\mathrm{a}}$

Linear (I)<smiles>C=Cc1ccccc1</smiles>

S2<smiles>O=CCCc1ccccc1</smiles>

(I)<smiles>CC(C=O)c1ccccc1</smiles>

(b)

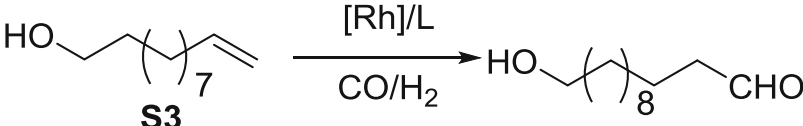

(l)<smiles>C=C(C)C(=O)OC</smiles>

S4<smiles>CC(=O)OCCC(C)C(C)=O</smiles>

(I)<smiles>CC(C=O)CC(C)CO</smiles>

(b)<smiles>COC(=O)C(C)(C)O</smiles>

(b)

\begin{tabular}{lcccccc}
\hline Run & Ligand (Substrate) & Temp. $\left({ }^{\circ} \mathrm{C}\right)$ & $\mathrm{CO} / \mathrm{H}_{2}(\mathrm{bar})$ & Time (hrs) & Conversion $^{\mathrm{b}}(\%)$ & 1:b selectivity \\
\hline 1 & $\mathbf{4 a}(\mathbf{S 2})$ & 100 & 10 & 16 & $99(85)$ & $34: 66$ \\
2 & $\mathbf{4 b}(\mathbf{S 2})$ & 100 & 10 & 16 & $99(80)$ & $25: 75^{\mathrm{c}}$ \\
3 & $\mathbf{4 a}(\mathbf{S 3})$ & 100 & 10 & 16 & $99(85)$ & $51: 49$ \\
4 & $\mathbf{4 b}(\mathbf{S 3})$ & 100 & 10 & 16 & $96(90)$ & $51: 49$ \\
5 & $\mathbf{4 a}(\mathbf{S 4})$ & 100 & 10 & 16 & $62(42)$ & $81: 19$ \\
6 & $\mathbf{4 b}(\mathbf{S 4})$ & 120 & 10 & 16 & $33(33)$ & $67: 33$ \\
\hline
\end{tabular}

${ }^{a}$ Conditions: $\left[\mathrm{Rh}(\mathrm{acac})(\mathrm{CO})_{2}\right]=2 \mathrm{mg}, \mathrm{L} / \mathrm{M}=4$, Solvent: toluene $(1 \mathrm{~mL})$. S2: styrene, S3: 1 -undecenol, S4: methyl methacrylate; ${ }^{b}$ Total conversion (conversion to aldehyde in parenthesis) \& regioselectivity were determined by proton NMR spectroscopy using $\mathrm{CH}_{2} \mathrm{Br}_{2}$ (equimolar to substrate) as an internal standard; ${ }^{\mathrm{c}}$ Regioselectivity was determined by GC.

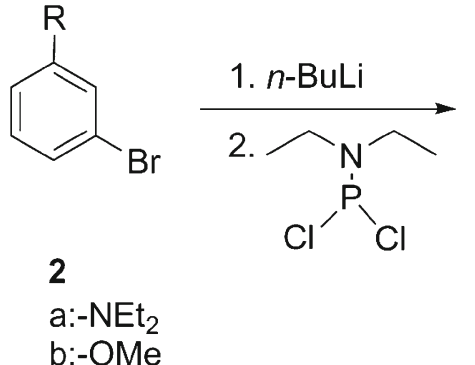

a:-NEt 2<smiles>[R]c1cccc(P(c2cccc([R])c2)N(CC)CC)c1</smiles><smiles>[R]c1cccc(P(OC)c2cccc([R])c2)c1</smiles>

Scheme 1. Synthesis of $m$-substituted phosphinites with electron donating functional groups.

sure. Next, the effect of temperature was investigated and it was found that the conversion as well as regioselectivity reduces at $80^{\circ} \mathrm{C}$. Increasing the temperature to $120^{\circ} \mathrm{C}$ showed similar trend with reduced conversion and selectivity. Thus, the best conversion of $94 \%$ could be obtained at a linear selectivity of 51\% (Table 1, run 2).

Along the same line, preliminary screening for $\mathbf{4 b}$ indicated an optimal ligand to metal ratio of 4 (Table 1 , run 9), although the conversion and selectivity was considerably poor as compared to 4a. Reducing syngas pressure to 5 bars at a $\mathrm{L} / \mathrm{M}$ ratio of 4 further reduced the conversion to $15 \%$ only, with $52 \%$ linear aldehyde (Table 1, run 11). Whereas, increasing the syngas pressure led to the best conversion of $87 \%$, without a penalty on regioselectivity (which was 54:46). Increasing the temperature to $120^{\circ} \mathrm{C}$ led to a better linear 


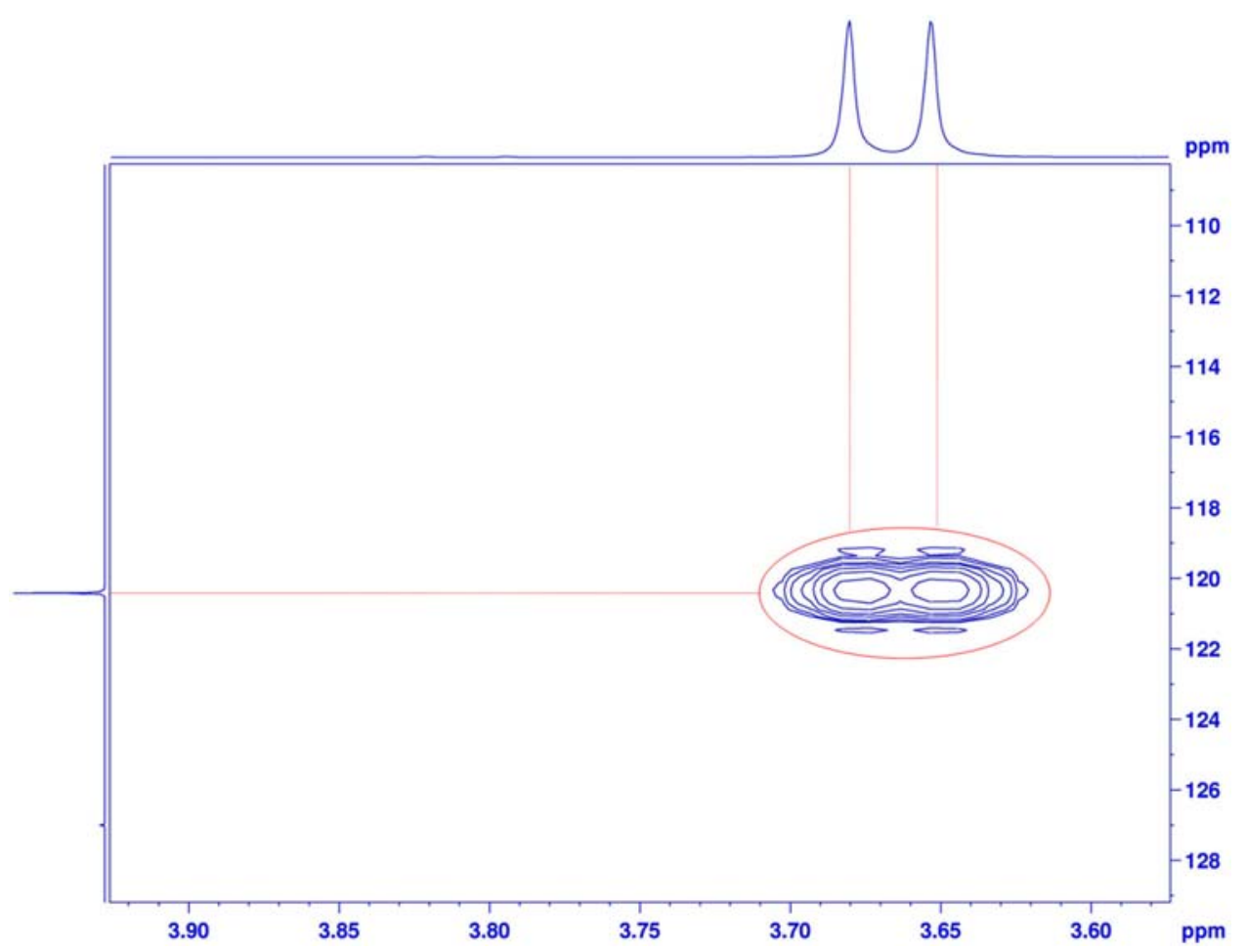

Figure 2. A long range P-H correlation (HMBC) spectrum of $\mathbf{4 a}$ depicting the phosphorus-proton cross peak.

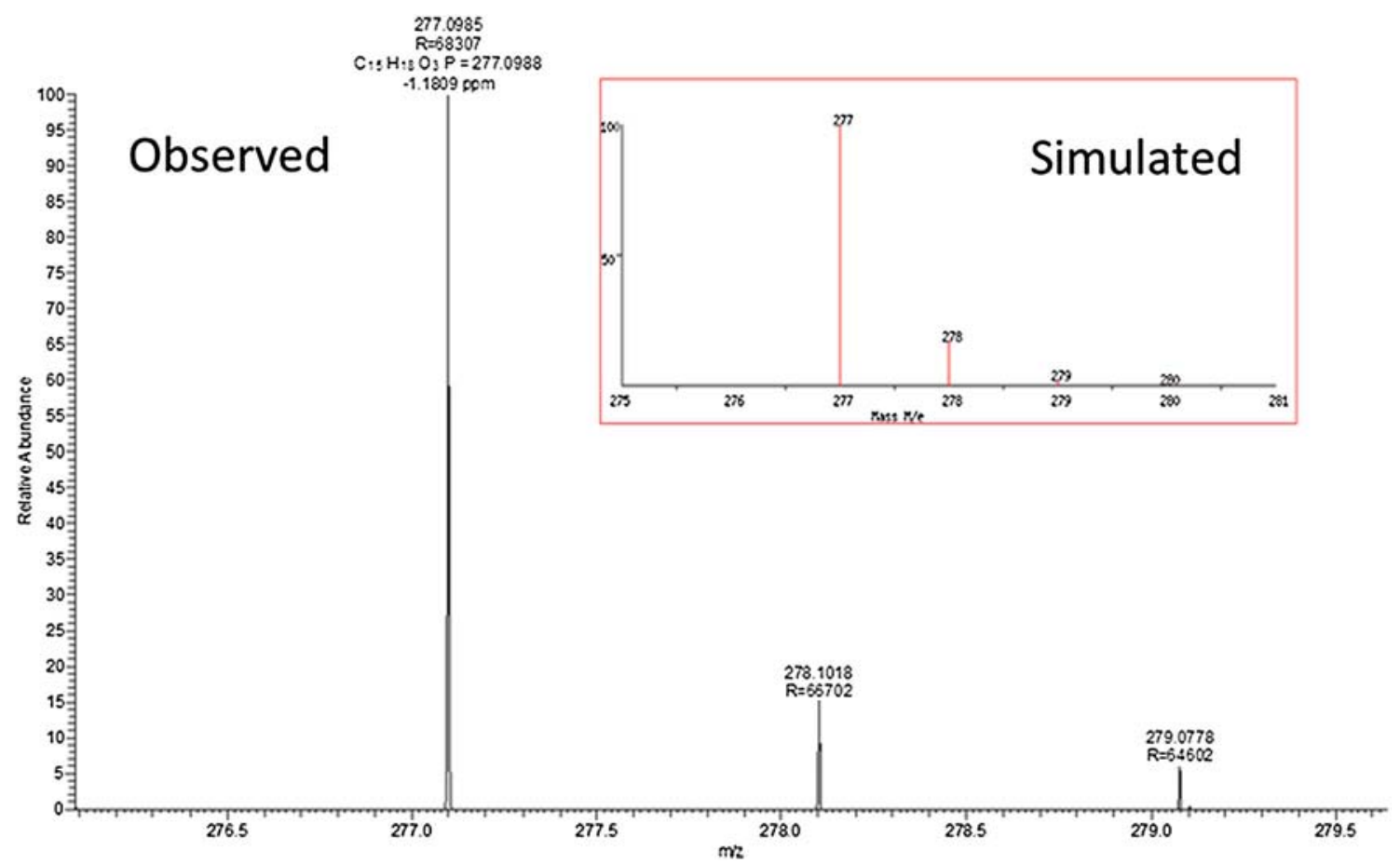

Figure 3. ESI-MS (+ve mode) spectrum of $\mathbf{4 b}$, depicting the observed and simulated (inset) spectra.

selectivity of $62 \%$, but at the cost of slightly reduced conversion (Table 1, run 13). Overall, the monodentate meta-substituted ligands were found to catalyze hydroformylation of 1-octene and the best linear regioselectivity of $62 \%$ was obtained while employing $\mathbf{4 b}$. The thus obtained regioselectivity compares well with literature reported ${ }^{19,24}$ monodentate phosphinite ligands 5, 6 presented in run 15 and 16 which are depicted in Chart 1 . These findings indicate that electron deficient phosphinites will be better suited for higher activities, whereas, electron rich sterically demanding phosphinites will be more effective for (regio)selectivity. 


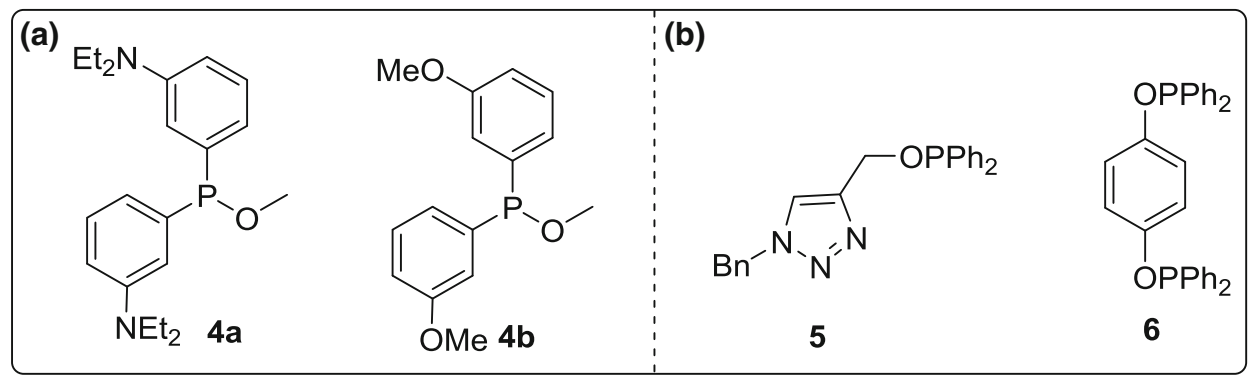

Chart 1. Ligands employed in the hydroformylation of 1-octene; (a) this work (left) and (b) phosphinites reported in the literature (right).

In our attempts to broaden the substrate scope, performance of $\mathbf{4 a}$ and $\mathbf{4 b}$ was evaluated in the hydroformylation of styrene (S2), 1-undecenol (S3) and a highly challenging 1,1-disubstituted electron deficient olefin, methyl methacrylate (S4). ${ }^{1}$ Hydroformylation of S2-S4 was performed under optimized conditions and Table 2 presents the important results. As a representative of aromatic substrate, hydroformylation of styrene using $\mathbf{4 a}$ was attempted, that led to quantitative conversion under optimized conditions (Table 2, run 1). An enhanced branch selectivity of $75 \%$ was obtained without compromising the activity when $\mathbf{4 b}$ was used as ligand. Functional olefins are of great interest as the resultant hydroformylation products can be used as monomer for polycondensation reactions. However, hydroformylation of functional olefins is more challenging, as the functional group can potentially poison the catalyst. To evaluate the performance of $\mathbf{4 a - b}$ in functional olefin hydroformylation, we choose 1-undecenol (S3) (undec-10-en-1-ol). Hydroformylation of S3 under optimized conditions revealed $85 \%$ conversion to 12 hydroxy dodecanal, without discriminating the linear over branched (Table 2, run 3) product. Similar results were obtained when $\mathbf{4 b}$ was employed as a ligand in the hydroformylation of $\mathbf{S 3}$ (Table 2, run 4). The thusprepared 12-hydroxy dodecanal is key intermediate to obtain a hydroxy-acid, which can be used as ABtype monomer for polyester synthesis. 1,1-disubstituted functional olefins are even more challenging for two reasons: i) due to two substituents on the same carbon atom, and they are sterically encumbered; ii) the functional group can bite back to the metal, leading to catalyst deactivation and loss of activity. Indeed, hydroformylation of methyl methacrylate (S4) using 4 a displayed reduced formylation activity of $42 \%$, while the linear aldehyde product was obtained with $81 \%$ selectivity (Table 2, run 5). Along the same line, $4 \mathbf{b}$ displayed moderate performance with $33 \%$ conversion to aldehyde and $67 \%$ linear selective product (Table 2, run 6). Thus, the phosphinite ligands $\mathbf{4 a}$ and $\mathbf{4 b}$ were found to catalyze the hydroformylation of routine substrates such 1-octene; more importantly, these ligands are able to catalyze hydroformylation of functional olefin, as well as a highly challenging 1,1-disubstuted functional olefins.

\section{Conclusions}

In summary, two step protocol to access meta-substituted phosphinites 3,3'-(methoxyphosphanediyl)bis $(N, N$-diethylaniline) (4a) and methoxybis(3-methoxyphenyl) phosphane (4b) in high yields has been established. Bromo-aniline and bromo-anisole were lithiated and treated with 1,1-dichloro- $N, N$-diethylphosphanamine to yield intermediate $3,3^{\prime}$-((diethylamino)phosphanediy 1)bis( $N, N$-diethylaniline) (3a) and $N, N$-diethyl-1,1 -bis(3-methoxyphenyl)phosphanamine (3b), respectively. Addition of methanol to $\mathbf{3 a}$ and $\mathbf{3 b}$ led to the generation of new resonance between 110-120 ppm in a ${ }^{31} \mathrm{P}$ NMR spectrum, indicating the formation of desired phosphinites (4a and $\mathbf{4 b}$ ). These findings were corroborated by proton and carbon NMR. Thus, the existence of $\mathbf{4 a}$ and $\mathbf{4 b}$ was unambiguously ascertained using a combination of 1-2D NMR and mass spectroscopy. The synthetic utility of the phosphinite ligands was demonstrated by evaluating $\mathbf{4 a}$ and $\mathbf{4 b}$ in the rhodium catalyzed hydroformylation of 1-octene. It was found that $\mathbf{4 a}$ is far more active (with 94-97\% conversion) than $\mathbf{4 b}$ under identical conditions. Although $\mathbf{4 b}$ led to poor activity, it displayed slightly better selectivity of $62 \%$ linear nonanal. In addition, $\mathbf{4 a}$ and $\mathbf{4 b}$ were found to catalyze the hydroformylation of styrene (S2), a functional olefin (S3) as well as a highly challenging 1,1-disubstituted functional olefin (S4).

\section{Supplementary Information (SI)}

${ }^{1} \mathrm{H},{ }^{13} \mathrm{C},{ }^{31} \mathrm{P}, \mathrm{HSQC}, \mathrm{HMBC}, \mathrm{COSY}$, NOESY spectra of $\mathbf{3 a}$, $\mathbf{3 b}, \mathbf{4 a}$ and $\mathbf{4 b}$, mass spectra of $\mathbf{4 a}$ and $\mathbf{4 b}$ are available at www.ias.ac.in/chemsci. 


\section{Acknowledgements}

Financial support from SERB-DST (SR/S2/RJN-11/2012 and EMR/2016/005120), India, is gratefully acknowledged. SSD, SP and SRG would like to thank UGC and CSIR, respectively, for the senior research fellowship. CSIR-National Chemical Laboratory is gratefully acknowledged for additional support. SHC is indebted to AvH foundation Bonn, Germany, for equipment grant.

\section{References}

1. Leeuwen P W N M 2004 In Homogeneous catalysis: Understanding the art (Dordrecht, The Netherlands: Kluwer Academic Press)

2. (a) Klosin J and Landis C R 2007 Ligands for practical rhodium-catalyzed asymmetric hydroformylation Acc. Chem. Res. 40 1251; (b) Mukaiyama T and Yamabe H 2007 Alkyl phosphinites: Versatile synthetic intermediates for dehydration condensation reactions Chem. Lett. 36 2; (c) Pedroni J and Cramer N 2015 Taddolbased phosphorus(III)-ligands in enantioselective $\operatorname{Pd}(0)$ catalysed C-H functionalisations Chem. Commun. 51 17647; (d) Castillon S, Claver C and Diaz Y 2005 C1 and $\mathrm{C} 2$ symmetric carbohydrate phosphorus ligands in asymmetric catalysis Chem. Soc. Rev. 34 702; (e) Grellier $\mathrm{M}$ and Sabo-Etienne S 2012 Dehydrogenation processes via $\mathrm{C}-\mathrm{H}$ activation within alkylphosphines Chem. Commun. 48 34; (f) Chikkali S H, van der Vlugt J I and Reek J N H 2014 Hybrid diphosphorus ligands in rhodium catalysed asymmetric hydroformylation Coord. Chem. Rev. 2621

3. Koshti V S, Mote N R, Gonnade R G and Chikkali S H 2015 Highly enantioselective palladium catalyzed synthesis of P-stereogenic supramolecular phosphines, self-assembly and impliaction Organometallics $\mathbf{3 4} 4802$

4. Omelanczuk J and Mikolajczyk M 1979 Optically active trivalent phosphorus compounds. Reactivity of alkylthio- and alkylselenophosphonium salts. The first stereospecific synthesis of a chiral phosphinite J. Am. Chem. Soc. 1017292

5. Jennings J R and Cozens R J 1996 The catalytic dimerization of acrylonitrile: III. Activity and selectivity of homogeneous catalysts derived from substituted aromatic phosphinites and phosphonites. Appl. Catal. A: Gen. 135163

6. Pandey S and Chikkali S H 2015 Highly regioselective isomerizing hydroformylation of long-chain internal olefins catalyzed by rhodium bis(phosphite) complex ChemCatChem 73468

7. Chikkali S H, Bellini R, de Bruin B, van der Vlugt J I and Reek J N H 2012 Highly selective asymmetric Rh-catalyzed hydroformylation of heterocyclic olefins J. Am. Chem. Soc. 1346607

8. (a) Agbossou-Niedercorn F and Suisse I 2003 Chiral aminophosphine phosphinite ligands and related auxiliaries: Recent advances in their design, coordination chemistry, and use in enantioselective catalysis Coord. Chem. Rev. 242 145; (b) Koshti V, Gaikwad S and Chikkali S H 2014 Contemporary avenues in catalytic
P-H bond addition reaction: A case study of hydrophosphination Coord. Chem. Rev. 26552

9. Tolman C A 1970 Electron donor-acceptor properties of phosphorus ligands. Substituent additivity J. Am. Chem. Soc. 922953

10. Tolman C A 1977 Steric effects of phosphorus ligands in organometallic chemistry and homogeneous catalysis Chem. Rev. 77313

11. (a) van den Goorbergh J A M and van der Gen A 1980 Ethyl 4-diphenylphosphinoyl-2-oxobutanoate: A convenient reagent for the synthesis of $\gamma$-ketoesters Tetrahedron Lett. 21 3621; (b) Bhattacharya A K and Thyagarajan G 1981 The Michaelis-Arbuzov rearrangement Chem. Rev. 81415

12. (a) Ugur I, Aydemir M, Nermin M, Durap F, Kayan C, Temel H and Baysal A 2013 Tunable ferrocenyl phosphinite ligands for the ruthenium(II) catalyzed asymmetric transfer hydrogenation of ketones J. Mol. Cat. A Chem. 379 225; (b) For a recent review, see: Adhikary A and Guan H 2015 Catalysis involving phosphinite based metallacycles ACS Catal. 56858

13. For a review on phosphinite derived pincer complexes in catalysis, see: Chakraborty S, Bhattacharya P, Dai H and Guan H 2015 Nickel and Iron pincer complexes as catalysts for the reduction of carbonyl compounds Acc. Chem. Res. 481995

14. Balakrishna M S, George P P and Shaikh M M 2005 A new diphosphinite derived from cyclohexane-1,4-diol: Oxidation reactions, metal complexes, P-O bond cleavage and X-ray crystal structures of $\mathrm{Ph}_{2}(\mathrm{E}=\mathrm{S}, \mathrm{Se})$ Polyhedron 24475

15. (a) Sato Y, Kawaguchi S I and Ogawa A. 2015 Photoinduced reductive perfluoroalkylation of phosphine oxides: synthesis of P-perfluoroalkylated phosphines using TMDPO and perfluoroalkyl iodides Chem. Comm. 51 10385; (b) Rajanbabu T V 2012 Phosphinite and Phosphonite Ligands In Phosphorus(III) Ligands in Homogeneous Catalysis: Design and Synthesis P C J Kamer and P W N M van Leeuwen (Eds.) (Chichester, UK: John Wiley \& Sons) Ch. 5 pp. 159-232

16. Drent E, van Dijk R, van Ginkel R, van Oort B and Pugh R I 2002 The first example of palladium catalysed nonperfectly alternating copolymerization of ethene and carbon monoxide Chem. Comm. 964

17. (a) Naik S, Durganna N, Mobin S M, Mague J T and Balakrishna M S 2012 Synthesis and transition metal chemistry of new bromo- and alkyl substituted phosphinite ligands Polyhedron 38 97; (b) Balakrishna M S, Panda R and Mague J T 2002 synthesis and derivatization, structures and transition metal chemistry of new large bite bis(phosphinite) derived from bis(2-hydroxy1-naphthyl)methane J. Chem. Soc. Dalton Trans. 4617

18. (a) Müller D, Guénée L and Alexakis A 2013 Practical synthesis of simplephos ligands: Further development of alkyl substituted phosphanamines Eur. J. Org. Chem. 2013 6335; (b) Zhou X, Lai R, Beck J R, Li H and Stains C I 2016 Nebraska red: a phosphinite based near-infrared fluorophore scaffold for chemical biology applications Chem. Comm. 5212290

19. Dubrovina N V, Domke L, Shuklov I A, Spannenberg A, Franke R, Villinger A and Boerner A 2013 New mono- 
and bidentate P-ligands using one pot click-chemistry: synthesis and application in Rh-catalyzed hydroformylation Tetrahedron $\mathbf{6 9} 8809$

20. Franke R, Selent D and Boerner A 2012 Applied hydroformylation Chem. Rev. 1125675

21. Hobuss D, Baro A, Axenov K V, Laschat S and Frey W 2011 P-Stereogenic pinene-derived phosphoramidites and their use in copper-catalyzed conjugate additions Eur. J. Inorg. Chem. 2011384

22. Saitoh T, Yoshida S and Ichikawa J 2006 Naphtthalene1,8-diylbis(diphenylmethylium) as an organic two electron oxidant: Benzidine synthesis via oxidative self-coupling of $N, N$-dialkylanilines $J$. Org. Chem. 71 6414

23. (a) Deng Y, Wang H, Sun Y and Wang X 2015 Principles and applications of enantioselective hydroformylation of terminal disubstituted alkenes ACS Catal. 5 6828; (b) Breit B and Seiche W 2001 Recent advances on chemo-, regio- and stereoselective hydroformylation Synthesis $\mathbf{1}$ 124

24. Khan S R and Bhange B M 2013 Selective hydroformylation-acetalization of various olefins using simple and efficient Rh-phosphinite complex catalyst. Tetrahedron Lett. 545998 